It often happens in practice that the clinical evidences of heart disease are masked or hidden by the conspicuous break-down of some neighbouring organs. The lungs are the organs which most frequently produce this complication. I have notes of three cases of hypertrophy and dilatation of the left cavities, in which no definite signs of such a condition were noticed during life. ${ }^{6}$ This so far agrees with what Dr. Fagge (vide supra) has written on the subject. The only symptom I can find common to them all was dyspncea-suffocating attacks of shortness of breath,which came on with varying frequency for several days before death. In all the cases there was a considerable quantity of fluid in the pleural cavities, and the lung tissue was collapsed to a greater or less extent. (In one case a portion of the right lung was " carnified.")

The generally accepted doctrine as to the etiology of dyspnoea in such cases is ably expounded by the late Dr. Fagge. ${ }^{7}$ In enlargement of the left heart slight excitement ofexertion on the part of the patient will produce an altogether disproportionate increase in the rate of the pulse, with at the same time a sensation of dyspnoa. Dr. Fagge explains these peculiarities as follows:- "In spite of its augmented frequency, the heart, after all, fails to forward the blood through its left chambers with needful rapidity; there is therefore an accumulation in the pulmonary vessels, and the right ventricle has to make increased efforts to propel its contents onwards. And as the result is a state of the pulmonary circulation identical with that which is produced in other cases by a deficient supply of air to the lungs, it is not surprising that the same feeling of shortness of breath is experienced." This explanation implies that the dyspnoa in these cases is associated with engorgement of the pulmonary vessels. I must take exception to this view, as one which is not applicable to two of the three cases I am here considering.

Physiologists assume, in calculating the work done by the heart, that in the healthy man the ventricles empty themselves of blood at each systole. We may probably accept their conclusions founded on this assumption when they deal with an organ of normal capacity. These data are, I think, erroneous when applied to an enlarged heart, especially when the enlargement is associated (as is mostly the case) with dilatation of the left ventricle. The solid contents of spheres vary directly as the cubes of their radii. If we take a distended heart cavity to roughly represent a sphere (the actual shape of the cavity does not greatly affect the result), we can readily understand how a very slight augmentation of its mean diameter will largely increase its capacity. For example, a ventricle with the capacity equal to the volume of a sphere of one-inch radius will contain, when distended, about four cubic inches of blood. If we now take a ventricle having a capacity equal to the volume of a sphere of two inches' radius, the contents of such a chamber would be upwards of thirty-three cubic inches; that is to say, the heart, if it emptied itself at each systole, in the former case would propel only one-eighth the quantity of blood that it would do under the latter circumstances. It must be within the experience of most of us to have irequently examined hearts the mean diameters of whose chambers, if not double their normal size, were at all events greatly increased. Now the carrying capacity of such dilating hearts increases at a far more rapid rate probably than their propelling power that is, than any compensatory hypertrophy of the muscular walls would be capable of adequately dealing with. The overtaxed ventricles of such enlarged hearts never quite empty themselves. There follows a condition of engorgement, not of the lungs in the first place, but of the heart itself. If, as mostly happens, the left ventricle is the one smitten by disease, in spite of its thickened walls and its enlarged chamber, a less volume of blood would be probably driven through the aorta and systemic vessels than in health, and an anæmic condition of the body would be the result. In some instances I have no doubt there is regurgitation through the mitral orifice and pulmonary congestion; but I desire it to be understood that this is an accidental and not a necessary sequence. In two of the three cases of cardiac enlargement I have just alluded to the lungs were pale and bloodless; yet the patients both suffered dyspncea before their deaths-a

6 One patient died of hæmorrhage into the pons Varolii and atheroma of the cerebral arteries; another, whose heart weighed $220 \mathrm{z}$., had sarcoma or the left kidney; the third had contracted granular kidneys, with a heart weighing $20 \mathrm{oz}$

7 Principles and Practice of Medicine, vol. ii., pp. $29,30$. ondition exaggerated by the presence of a considerable quantity of fluid in the pleural cavities, although we must possibly seek for its origin in the engorgement of the heart and the consequent withdrawal of so much blood from the general circulation. It is this chronic distension of the dilated heart in a normally-sized psricardial sac which is doubtless accountable for the pseudo-friction sound ccasionally heard in such cases.

Brighton.

\section{TREATMENT OF UTERINE FIBRO-MYOMA.}

\section{Bx J. KNOWSLEY THORNTON, M.B., C.M.,} SURGEON TO THE SAMARITAN FREE HOSPITAL.

BEFOnE proceeding to the consideration of the surgical treatment of this common disease, I will say a few words about the medical and dietetic treatment, because, seeing as I do a large number of cases in consultation with $\mathrm{my}$ medical brethren, and of cases who come to me from them, for an opinion as to whether any active treatment is necessary or advisable, I am much impressed with the fact that a great many of the patients, who might lead comfortable lives if they were wisely guided as to their diet and general method of life, are allowed or advised to follow a course which makes them worse instead of better, and tends to bring them into the hands of the surgeon.

When a patient presents herself with a small or moderate sized tumour I always begin by asking the following questions: 1 . Are you getting so much larger that you have to alter your clothes? 2. Do you suffer any inconvenience from your increased size? 3. Do you suffer pain generally or at the monthly periods? 4. Are the monthly periods regular as to time, and are they prolonged or excessive? 5. Is the action of the bowels or that of the kidneys or bladder interfered with; and are there pressure symptoms, such as swelling of the legs and feet? When these questions have been answered, $I$ ask for a sketch of the usual diet and the habit as to stimulants, and then as to the amount of rest taken at the onset of the period and during the flow. Finally, I inquire whether any special medical treatment has been adopted. If the first three questions are answered in the negative, as they are in the great majority of cases, the chances are that, with a little good direction as to medicine, food, and drink, there will be little need to take into consideration any surgical treatment. Now, I find that in the great majority of cases the patient has been told that she must live well, and take plenty of wine, beer, or spirit, to make up for the free periods and support her strength. There cannot be a greater mistake. The disease, in its early stages always, and in its later stages generally, is found in patients who have a tendency to make flesh and blood fast, and if their alvine and urinary evacuations are carefully regulated, and they are advised to take red or butcher's meat sparingly, and live chiefly on fish, white meat, eggs, milk, and vegetables, and practically wear the "blue ribbon," or only take the smallest quantity of wine or weak spiritand-water, when their digestion is aided by so doing, the disease will stand still, and their tumours give them little or no inconvenience. They should also be encouraged to take regular walking exercise in the intervals between the periods, but to remain if possible at perfect rest when they occur, and more especially during the congestion which precedes the flow. It is also a common practice to give ergot during the menstrual flow, and I believe it is a great error. The growth cannot then be starved by contraction of the uterine muscle, for it is by its physiological nerve stimulation abundantly supplied with blood, and at the most the flow is checked, which is nature's natural outlet for the increased bloodsupply, and thus is increased the congestion upon which the growth teeds. The ergot should be given with some nux vomica, which aids its action, and with other vegetable bitters, which prevent it from disagreeing with the stomach, in the intervals between the periods, and a tonic contraction is kept up in the uterine muscular fibres which starves the growth. Then, again, it is a common practice to give these patients iron, because they are often anæmic from loss of blood. I believe this is just as harmful as giving them red meat and wine. Anyone who has watched and studied

I Read before the Cambridge Medical Society, June 5th, 1886. 
many of these cases will see that iron, red meat, and wine are the things upon which fibro-myomata grow, flourish, and bleed most. It would occupy too much time to inquire thoroughly into the life-history of these growthe, but I am convinced that the ovarian nerve stimulus, which finds its natural outlets in regular menstruation, married life, and maternity, are their great enemies; and if we argue back from these, it is easy to see why iron and meat, the bloodgivers, and wine, the great stimulator of the circulation, feed and stimulate the nerve forces, which in the majority of these patients have not and cannot have their natural outlet, and so, like all forces which are excited only to waste, run riot in disease. I do not mean to say that all cases can be prevented from growing by such simple measures, but I do unhesitatingly say that all patients will be made more comfortable by strictly adhering to them, and the large majority will find that they can so effectually check the progress of the growths that they will elect rather thus to regulate their lives than face the serious risks of surgery. I frequently see a patient with a tumour growing fast with all sorts of pelvic pains and discomforts, and with hrmorrhage which threatens to become exhausting. I sketch out a line of treatment, especially dwelling upon the importance of avoiding stimulants and the excessive use of red meat, and advise her to see me again in a few months, saying that it will then be time enough to talk about surgery. When the time comes for the second consultation, the patient comes, not to talk about surgery, but to say how much better she is, and to ask for some further and perhaps more stringent and definite rules as to diet, or for some variation in the aperient or tonic.

In passing now to the surgical treatment of those cases which have gone beyond milder measures, when they first seek special advice, or which the milder measures have failed in, I propose to take as my text three cases which I have recently operated upon, because it is quite impossible to deal with the whole subject in one short paper, and these three cases illustrate in a remarkable manner some of the practical difficulties of diagnosis, and some of the most important pathoiogical considerations.

The first case is one of a very rare class, in which subperitoneal and pedunculate tumours grow so fast as to cause marked emaciation, and clearly such cases are only amenable to surgical treatment, and that of the most prompt and radical kind. I have selected this and the other two cases about to be related because they equally illustrate the impossibility of always making an accurate diagnosis between uterine and ovarian tumour, and because I hold that when such cases are met with immediate surgical treatment is the only proper course.

CAsE 1.-H, F-_- single, aged thirty-six, was admitted into the Samaritan Free Hospital, under my care, on March 21st, 1886 . She was markedly emaciated, especially about the face and bust, and said that she was losing flesh fast. For the last twelve months she had suffered from frequent attacks of bilious vomiting, with much flatulence and persistent constipation. She had never had any serious illness, and the lungs, heart, and kidneys were healthy. Her father died of phthisis at forty-one, and her only sister at twenty-one. Her mother, aged sixty-eight, was alive. One of her mother's brothers also died of phthisis. With the exception of the attacks of sickness, she had been in her usual health till two months before admission, when she noticed a lump in her abdomen, which fell over from side to side when she turned in bed. It increased rapidly in size after she first noticed it, and another similar lump soon appeared and also grew fast. Menstruation began at eleven and was always very free and accompanied by much pain till six or: seven years back, when the pain and quantity both decreased, but the periods continued to be sufficiently copious and quite regular. On examining the abdomen, I found two large solid tumours: one lying rather to the right and in the lower abdomen; the other above it, entirely in the left side, and passing up under the ribs. Between the two, and somewhat to the left of the median line, there was a third small hard body of irregular outline, which I believed to be the uterus, and the use of the sound verified this opinion. The cervix was found by vaginal examination to be small and soft and high up on the left side. The pouch of Douglas was occupied by a hard rounded mass, which was evidently the lower part of the tumour in the right side of the abdomen. Looking to the position of the two tumours, their relations to the uterine body, the menstrual history, and their rapid growth, which was coincident with emaciation, I came to the conclusion that they were solid ovarian tumours. On March 24 th $I$ made the usual median incision and found that the two large growths were pedunculated fibromyomata, that there was a third similar growth between them, and that the body of the uterus was covered with other small growths. Both ovaries were large, but fairly healthy. I at once decided to perform hysterectomy, as I could include the whole mass in the wire of Koeberlé's serré-noeud, leaving no tied stumps in the peritoneum; and when this can be done complete supra-vaginal hysterectomy is an easier and safer operation than the removal of outgrowths with vascular pedicles, which have to be ligatured and returned, together with the stumps of the ovaries and tubes, which it is necessary to remove in a case of the kind in order to stop the growth of the smaller tumours on the uterine body. The mass when removed weighed just under $7 \mathrm{lb}$. The patient, who was a nervous and excitable woman, had a temperature of $103^{\circ}$, with a pulse of 108 , at the morning visit on the day after the operation, but it fell at oncs when some pounded ice was applied to the head in a piece of mackintosh, and she made an uninterrupted recovery.

In this case I am certain that an absolute diagnosis was impossible until the abdomen was opened; and though I did not exclude from my diagnosis the possibility of the tumours being fibro-myomata, their general characters, positions, and rapid growth made it more probable that they were solid ovarian sarcomata. This leads me into a short digression from the proper subject of my paper for the purpose of discussing a most important practical point. I have long been in doubt whether it is right to operate upon solid ovarian sarcoma, because, if the operation is immediately successful, the patient is nearly certain to die with recurrent sarcomata in the glands and in various parts of the body in from twelve to fifteen months. Of course it is impossible to say whether life would be more prolonged if the original tumour were left alone; but 1 fancy not, and that, on the whole, the suffering would be greater with this enormous abdominal mass present. It was not this consideration, however, which turned the balance in the case just narrated in favour of operation, but the fact that, among many recurrent cases (which can be consulted in my published ovariotomy tables), I have one signal success in the case of a young married lady, who was almost in a dying state when I operated, and from whom I removed. a large brain-like sarcoma of one ovary, separating extensive adhesions which involved the other ovary. She had two girls before the operation, a third within two years, and quite recently, on the sixth anniversary of the operation, she sent me the photograph of a fine baby boy, who is the only male heir to his father's name, and whose advent had long been keenly desired; one such success makes up for many sad failures, and now the instance I have recorded is another encouragement to operate in these cases, for it would have been a terrible thing had I left this poor woman to perish, believing the tumours were ovarian sarcomata, when they were simple fibro-myomata and radically curable.

The second case which I am about to record is another example of the impossibility of certain diagnosis in some cases, and it again carries me beyond my subject; but the lessons it teaches are so bound up with it that I feel that no apology is necessary for relating it.

CASE 2.- E. A. J- aged forty-five, married, and mother of one child twenty-four years of age, was admitted into the Samaritan Hospital, under my care, on April 3rd, 1886. She was not emaciated, but had a very sallow, unhealthy appearance. She had suffered for some years from sickness, flatulence, constipation, and pain after food. The heart and lungs were healthy, but thekidneys were daily secreting from twenty to thirty ounces of pale, highly albuminous urine, with a specific gravity of 1010 , and she had for the last three years been unable to empty the bladder without the aid of manual pressure over the lower abdomen. She had married at the age of nineteen, and had one child; then had. been a widew from twenty-one to twenty-nine; subsequently she married again, and had a miscarriage. She was regular after this till two years before admissiou, when coloured discharge became almost constant, and so continued. The father's family was phthisical; the mother was living, aged seventy-seven; and six of her own brothers and sisters had died, many of them of phthisis. She had had a lump in her abdomen for fourteen years; it was small and hard at first, and to the right of the median line; its growth had been very irregular-fits of rapid increase, followed by complete arrest. When growing fast it caused 
much pain, and she had often been laid up for months at a time with the pain. Nine years ago she consulted one of the most distinguished authorities, and was told to wait for the menopause; and in October, 1885, she again consulted him, and the same advice was given. She was keenly anrious for operation, because of the attacks of pain and the increasing renal and bladder trouble. I found the abdomen occupied by a large irregularly-lobed tumour, with the bladder drawn up on its anterior surface; the tumour svidently contained a large quantity of fluid. Vaginal examination revealed a large soft fluctuant swelling pressing down between the bladder and cervix, so as to almost obliterate the latter, and a harder mass behind the os. The sound passed a little over three inches, and apparently into the centre of the mass, for the slightest touch on the abdominal swelling at once moved its handle. Looking to the long history, the evident opinion of the authority mentioned above, and the vaginal relations, I came to the conclusion that it was an old fibro-myoma which had become cystic; and as these tumours usually then grow very rapidly, and are quite as dangerous to life as the ovarian cysts, 1 had no hesitation in assenting to her wish that it should be removed, though I was fully prepared for a serious operation, and was very anxious as to the behaviour of the evidently damaged kidneys. I operated upon the 7 th of April, and, after working hard for three hours and a half, slicceeded in removing the greater part of what $I$ have no doubt was a papillomatous cyst of the right ovary embedded in the broad ligament, as they so often are, and united by firm fibrous tissue to all the neighbouring organs, the adhesions having become denser and denser with the repeated attacks of pain (? peritonitis), and the uterus and bladder having been drawn out over the tumour, so that I had to remove the former and peel back the latter. In the course of the operation I tied both uterine arteries (the first time I have ever knowingly ligatured them), and exposed several inches of the right ureter, distended with urine. I was unable entirely to remove the cyst growing between the bladder and cervix, and this brought about a fatal result, for it filled gradually with ovarian fluid and blood; the mixture putrefied, and just when I thought she had got oner her dangers, it was suddenly discharged into the peritoneum during the first action of the bowels on the sixth day, and she collapsed and died within an hour.

Here, again, we have a case evidently difficult to distinguish from a fibro-myoma in its early growth, and I am sure quite impossible to distinguish from a fibro-cyst of the uterus at the time it came under my care. I have operated upon many of these cases of ovarian or other cysts embedded in the broad ligament and without a pedicle, and though their enucleation requires care and is tedious, they usually recover well if only they are taken in time-i.e., while their connexions are mere loose cellular tissue; and I have no doubt that this poor woman might have been saved many zears of misery, ending in a sudden death, and $I$ the misfortune of an unsuccessful case, if only she had been lucky enough to fall into the hands of someone courageous enough to attack a somewhat doubtful case. The kidneys threatened to cease secreting for the first few days after the operation, and then, as if rejoicing in the unaccustomed freedom from obstruction, poured out an abundance of fairly healthy urine with a much-increased specific gravity; and while I was welcoming this new feature of hope the final catastrophe occurred. It is a combination of hysterectomy with incomplete ovariotomy, and, like a good many operations in the present practice of abdominal surgery, very difficult to classify for statistical purposes. It should be borne in mind that cases like this, though they may not kill the patient by rapid and excessive growth, may be slowly and surely doing so by pressing on and obstructing the ureters, and that the same pathological condition is brought about by many a large solid fibro-myoma, which gives apparently little inconvenience, and certainly neither causes severe pain nor danger from its size or from hæmorrhage -the three symptoms in these cases which have been over and over again insisted on as the only justification for operative interference.

( $T o$ be concluded.)

AT an inquest held at Burton on the 15th inst. on the body of James Sproule Smythe, a surgeon, who for some time had been in practice in the town, and whose death occurred on the previous day from prussic acid, the jury returned a verdict of " Death from misadventure."

\section{ON VICARIOUS BLEEDING FROM THE} UNDER LIP,

\section{WITH CASES, AND REMARKS ON THE MIODERN} TREATMENT OF HXMORRHOIDS.

Bx ALEXANDER HARKIN, M.D., F.R.C.S., CONSULTINGEPHYSICIAN TO THE MATER IXEIRMORUM HOSPITAL, BELTAST.

CASE 1.-Mrs. M-, aged thirty-eight years, of bilious temperament, sallow complexion, dark hair and eyes, the mother of six children, called on me early in March, 1885. Before her marriage she had suffered from hæmorrhoids, and during her first and subsequent pregnancies from hepatic congestion and occasional hæmorrhage from the bowels, which frequently gave me some anxiety on her account. Among other troubles, in 1880 she was prostrated with profuse hæmorrhage from a cluster of varicose veins connected with the left femoral vein and close to the kneejoint. On this occasion she presented every sign of debility and anæmia: blanched cheeks and lips, sunken features, compressible and feeble pulse, undue palpitation of the heart on the slightest exertion, continuous headache, and frequent vertigo. She attributed her exhaustion to a profuse bleeding from the left under lip, occurring at every meal, and generally continuing for ten minutes each time. On examination $I$ found a slight abrasion at the junction of the epidermis with the lining membrane of the lip, about half the size of a threepenny coin, from which the flood flowed freely. Mrs. M- - had removed from my neighbourhood two years previously, and, as the hæmorrhase from the piles had again become troublesome, acting on the advice of a physician of experience, she entered the Royal Hospital, Belfast, in February, 1883, where soon after the offending growths were deligated by one of the attending surgeons to that institution. After her return home in April, she experienced complete relief for a short time only, irritation about the anus occurring occasionally, and now and then a slight discharge of blood from the nostrils; but in the following June her left lip became painful, and blood began to ooze from it once or twice in the week; the intervals then became gradually shorter, the drain occurring every day, and for many weeks before her visit to me the discharge reappeared at every meal, or when accidentally the lip was hurt. Having from previous lengthened experience acquired a thorough knowledge of the patient's constitution and requirements, I did not hesitate in adopting a plan of treatment. I ordered the immediate application of a blister, 8 in. by 4 in., for eight hours over the region of the liver, to be followed by cotton-wool dressing. On visiting Mrs. M- next day, I was informed that from the moment free vesication was established all labial hæmorrhage had ceased, and a return of health began to be felt. I then prescribed the use of chlorate of potash and iron in liberal doses; her colour and bodily strength soon reappeared, her headache and vertigo troubled her no more, and, with the exception of an occasional feeling of pain at the seat of discharge in the lower lip, she has not had a recurrence of any of her former ailments. In January last she gave birth to a male child without any unusual trouble, and up to the present date (a period of two years and seven months) there has not been even the slightest sign of the hæmorrhage.

CASE 2.-Mrs. McD-- - aged thirty-six years, mother of six children, sent for me on March 8th, 1886. I found her contined to bed, pallid and exhausted from a profuse discharge of blood from the rectum, which had continued for several days, having delayed from motives of delicacy to send for medical advice; the blood accompanied every evacuation and frequently after feeling a desire the motion consisted of blood alone, often to the amount of three or four ounces. On examination I found a fringe of external piles surrounding the aperture of the rectum, and inside the sphincter a number of knotty tubercles, from one of which red arterial blood flowed freely. In this, as in the former case, $I$ immediately applied a blister over the region of the liver, and ordered as an adjuvant a mixture of tincture of perchloride of iron and chlorate of potash solution. The relief was immediate, and the patient very soon recovered her natural colour and strength, and was able to take out-door exercise. At the end of a fortnight, however, I was again called to the 